\title{
Different Continuous Positive Airway Pressure Titration Modalities in Obstructive Sleep Apnea Syndrome Patients
}

\author{
Hadeer Ahmed Elshahaat $(\mathbb{D}$ \\ Tarek Abd El-Hakeem Mahfouz \\ Ashraf Elsyed Elshora \\ Amany Shaker
}

Chest Department, Zagazig University's Faculty of Medicine, Zagazig, Egypt
Correspondence: Hadeer Ahmed Elshahaat Chest Department, Zagazig University's Faculty of Medicine, Zagazig, Sharkia, 62725, Egypt

Tel +20 1067308630

Email dr.hadeer_elshahaat@yahoo.com
Background: Patients with obstructive sleep apnea syndrome are mainly treated with continuous positive airway pressure. Polysomnography-guided full-night manual titration is the gold standard for continuous positive airway pressure titration, but it is cost-, time-, and effort-consuming. Alternative ways of titration are easier with less cost, time, and effort. In the era of the COVID-19 pandemic, the need to establish more safe strategies is increased.

Aim: To choose a rapid, efficient, simple, and safe method with less effort and cost in the measurement of a suitable level of positive airway pressure in the management of obstructive sleep apnea syndrome.

Methods: This study enrolled 48 adult patients who had been diagnosed with obstructive sleep apnea syndrome at our sleep unit and were candidates for treatment with continuous positive airway pressure according to AASM 2008 after exclusion of other sleep-related breathing disorders. All patients underwent both laboratory full-night manual titration and auto-titration (by Prisma20A of WEINMANN medical technology, Germany). Manual titration pressure and $\mathrm{P} 95$ of auto-titration were obtained and compared with calculated pressures by five predictive formulas (Miljeteig and Hoffstein, Sériès, Stradling, Loredo, and Lee).

Results: Patients included in the study were 25 females (52.1\%) and 23 males (47.9\%) with a mean \pm SD of age of $49.98 \pm 10.36$ years. Mean \pm SD of manual pressure was $10.44 \pm 2.49$ $\mathrm{cmH}_{2} \mathrm{O}$, $\mathrm{P} 95$ was $10.16 \pm 2.64 \mathrm{cmH}_{2} \mathrm{O}$, and calculated pressures by different equations were: Miljeteig and Hoffstein, 8.53 \pm 2.03 ; Sériès, 11.40 \pm 1.81 ; Stradling, 9.68 \pm 1.65 ; Loredo, 9.90 \pm 1.79 ; and Lee, $10.61 \pm 2.68 \mathrm{cmH}_{2} \mathrm{O}$. No significant differences were reported between manual pressure and pressures of auto-titration with Sériès, Stradling, Loredo, and Lee equations ( $p=0.112,0.09,0.212,0.213$, and 0.657 , respectively).

Conclusion: Auto-titration can be used as an effective alternative to manual titration with less cost and effort and is more comfortable to patients. Predictive formulas can be used instead of standard and auto-titration especially in resource-limited facilities and in pandemics.

Keywords: obstructive sleep apnea syndrome, continuous positive airway pressure, manual titration, auto-titration, predictive formulas

\section{Introduction}

Obstructive sleep apnea syndrome (OSAS) is a major health problem, which is associated with various comorbidities, including increased metabolic and cardiovascular problems, health care fees, traffic accidents, and risks of mortality. ${ }^{1}$ The recommended management for most obstructive sleep apnea patients is continuous positive airway pressure (CPAP) as it relieves obstruction of the upper airway by 
elevating intramural pressure, leading to splinting of the airway. $^{2}$ In order to initiate treatment with CPAP, effective pressure that eliminates most obstructive events must be titrated previously. ${ }^{3}$

An attended diagnostic polysomnogram (PSG), followed by a second attended full-night with PSG guidance and physician supervision to titrate the adequate CPAP manually, is the gold standard for diagnosis and treatment of OSA. ${ }^{4}$ It is cost-, effort-, and time-consuming, and leads to a long waiting list, which delays initiation of the CPAP treatment. ${ }^{5}$

The search for feasible techniques to replace a standard technique has intensified in the last few years. Automatic titration and therapeutic pressure calculation using predictive formulas have been proven as alternative approaches. ${ }^{6}$

Without the intervention of a specialist, the automated positive airway pressure (APAP) device constantly adjusts the effective pressure to the patient's needs based on changes in airflow resistance. The use of APAP is based on the principles of feasibility and cost-effectiveness. ${ }^{7}$

Various predictive formulas were established previously, based on different parameters to predict a therapeutic CPAP level such as body mass index (BMI), neck circumference (NC), the lowest oxygen saturation, and other parameters. The accuracy of these formulas, however, has not compelled most practitioners to incorporate them into standard medical practice. ${ }^{4}$

In some patients, calculated CPAP can be beneficial in treating OSAS, but automated positive airway pressure (APAP) devices are used more commonly to reduce the requirement for a CPAP titration study. This could be due to APAP's advantage over predictive equations in adjusting for OSAS night-to-night variability. ${ }^{4}$

Other methods being considered for their potential to decrease costs and improve accessibility include split-night PSG (SPL), unattended home partial sleep monitoring (UHPSM), and home CPAP auto-titration (CPAP autotitration). However, concerns have been raised about SPL due to deficient diagnostic sampling and deficient time for titration; also, it has been applied only in certain conditions. UHPSM and home auto-titration have been promoted as ways to decrease costs in the evaluation of OSAS, but they are less accurate than full-night PSG and SPL-PSG and are prone to loss of data. ${ }^{8}$

This study was set out aiming to choose a rapid, efficient, simple, and safe method with less effort and cost in the measurement of a suitable positive airway pressure level for OSAS patients' management.

\section{Patients and Methods}

\section{Population of the Study}

Our sleep unit was the first established unit in the Sharkia Governorate at the end of 2015. This was the first study to discuss the comparison between different titration modalities and their efficacy for our patients. At the beginning of our study, from our sleep unit records, 100 patients had been diagnosed with obstructive sleep apnea syndrome and were candidates for treatment with CPAP according to the American Academy of Sleep Medicine (AASM 2008). ${ }^{9}$ Ten patients who had daytime hypoventilation with the possibility of obesity hypoventilation were excluded. The titration study failed in seven patients due to high residual apnea/hypopnea index (AHI/hr) ( 2 patients) or short sleep time ( 5 patients); in 3 of them it failed during auto-titration and in 4 during manual titration. Five patients refused to complete the titration study, as it required several nights to complete the study. After the beginning of the COVID-19 pandemic at the end of 2019, we were obligated to postpone most of the titration studies especially at periods of outbreaks. Health resources, institutions, and most of the health care teams were directed to face the pandemic. This led to interruption of the titration study of the 30 patients who had been diagnosed before the beginning of the COVID-19 pandemic. Finally, 48 patients were enrolled in this study after calculation of sample size using OPEN EPI at power $80 \%$ and CI 95\%. They were 25 women and 23 men, ranging in age from 27 to 67 years, and their mean \pm SD of age was $49.98 \pm 10.36$ years.

\section{Inclusion Criteria}

Patients who had been diagnosed with obstructive sleep apnea syndrome by polysomnography after suspicion by different scores according to AASM 2014 and were candidates for CPAP treatment according to AASM 2008 were included.

- According to AASM (2014), ${ }^{10}$ diagnosis of OSAS was established if:

- An AHI of $\geq 15$ events $/$ hr regardless of associated symptoms.

- Or an AHI of $\geq 5$ events/hr with the classic OSAS manifestations.

- According to AASM (2008): ${ }^{9}$

- Indications of CPAP are the treatment of severe and moderate OSAS [standard] as well as mild OSAS [option]. 
- CPAP is also used to improve sleepiness [standard], quality of life [option], and blood pressure in hypertensive individuals with OSAS as an adjunctive therapy [option].

\section{Exclusion Criteria}

1. Patients who had other sleep breathing disorders (central sleep apnea, obesity hypoventilation syndrome, and patients suffering from overlapping disorders such as chronic lung diseases).

2. Patients who were contraindicated to use CPAP. Contraindications: ${ }^{11}$

Absolute $\bullet$ Inability to fit mask $\bullet$ Respiratory or cardiac arrest

Relative $\cdot$ Uncooperative, agitated $\cdot$ Inability to protect airway - Unstable medical circumstances (uncontrolled arrhythmia, hypotensive shock, ischemia, or upper gastrointestinal hemorrhage) $\bullet$ Swallowing difficulties $•$ Profuse secretions $\bullet$ Failure of multiple organs $\bullet$ Recent surgery for the upper gastrointestinal tract or upper airway.

Study Design This study is a prospective cross-over clinical trial conducted in the unit of sleep-disordered breathing at Chest Department in Zagazig University Hospitals, in the period from October 2018 to June 2020. Approval was obtained from the administrative council of the chest department and institutional board review of Zagazig University (ZU-IRB \#4745/30-7-2018). Patients included in this study gave their informed and signed consent. This study was conducted in accordance with the Declaration of Helsinki.

\section{Study Protocol}

- The following data were collected from the records:

- Full history (especially daytime and night symptoms of sleep breathing disorders, and history of comorbidities), full clinical examination, involving body mass index (BMI, $\mathrm{kg} / \mathrm{m}^{2}$ ), and routine laboratory investigations. Values of OSAS suspicion (by Epworth sleepiness scale (ESS) and STOP-BANG score) also were recorded, and lastly diagnostic PSG data, which were gathered at the sleep unit of our chest department by SOMNO Screen ${ }^{\mathrm{TM}}$ Plus (SOMNO Medics, Germany), and patients were diagnosed with obstructive sleep apnea according to AASM (2014) criteria. ${ }^{10}$

- The following was done for all patients:

- Continuous positive airway pressure titration by three different methods (manual, auto-titration, and predictive formulas).
Before titration, the patient was informed about OSAS risk factors, history and consequences, explanation about CPAP, its benefits, hazards of neglecting treatment, different types of interface, and side effects.

\section{The Manual Technique of Titration}

The used device for titration was Prisma20A of WEINMANN medical technology, Germany. It was connected with the VPAP Tx lab system under full-PSG monitoring in our sleep lab, and conducted through an oronasal mask. This is the gold standard for CPAP level measurement.

The titration of CPAP was done according to the 2008 AASM manual titration recommendations as follows: titration was started by pressure $4 \mathrm{cmH}_{2} \mathrm{O}$ and pressure elevated gradually every 5 minutes by $1 \mathrm{cmH}_{2} \mathrm{O}$ guided by respiratory events till reaching optimal titration pressure. ${ }^{9}$

\section{Auto-titration}

Lab-attended auto-titration without monitoring by PSG but with monitoring of patient position and assessment of realtime leakage for 3 nights was done. This was recorded under the overnight supervision of a technologist with a device (Prisma20A of WEINMANN medical technology, Germany).

Minimum and maximum APAP pressures were adjusted at $4 \mathrm{cmH}_{2} \mathrm{O}$ and $20 \mathrm{cmH}_{2} \mathrm{O}$ for all patients. At the end of each treatment session, P95, which is the pressure that abolishes all obstructive events of the upper airway for more than $95 \%$ of the time, and other APAP titration data were downloaded (usage hours, leak, residual AHI).

If the median leak rate was more than $24 \mathrm{~L} /$ minute and/ or the total time of recording was less than 5 hours, the auto-titration was judged "unsuccessful". ${ }^{12}$

\section{Mathematical Equations}

Predicted CPAP ( CPAP $\left._{\text {pred }}\right)$ was determined for all patients using five prediction algorithms, which were recommended from the published studies:

» Miljeteig and Hoffstein equation: ${ }^{13} \mathrm{CPAP}_{\text {pred }}$ $\left(\mathrm{cmH}_{2} \mathrm{O}\right)=$

$$
(0.16 \times \mathrm{BMI})+(0.13 \times \mathrm{NC})+(0.04 \times \mathrm{AHI})-5.12
$$

» Sériès equation: ${ }^{14} \mathrm{CPAP}_{\text {pred }}\left(\mathrm{cmH}_{2} \mathrm{O}\right)=$

$$
(0.193 \times \mathrm{BMI})+(0.077 \times \mathrm{NC})+(0.02 \times \mathrm{AHI})-0.611
$$

» Stradling equation: ${ }^{15} \mathrm{CPAP}_{\text {pred }}\left(\mathrm{cmH}_{2} \mathrm{O}\right)=$ 


$$
(0.048 \times \mathrm{ODI})+(0.128 \times \mathrm{NC})+2.1
$$

") Loredo equation: ${ }^{16} \mathrm{CPAP}_{\text {pred }}\left(\mathrm{cmH}_{2} \mathrm{O}\right)=$

$$
\begin{aligned}
& 30.8+(\mathrm{RDI} \times 0.03)-(\text { nadirO2saturation }(\%) \times 0.05) \\
& \quad-(\text { meanO2saturation }(\%) \times 0.2)
\end{aligned}
$$

» Lee equation: ${ }^{17} \mathrm{CPAP}_{\text {pred }}\left(\mathrm{cmH}_{2} \mathrm{O}\right)=$

$$
\begin{aligned}
& 6.656+(0.156 \times \mathrm{BMI})-(0.071 \times \operatorname{minimalSpO} 2(\%)) \\
& +(0.041 \times \mathrm{RDI})+(0.094 \times \mathrm{ESS})
\end{aligned}
$$

Where: BMI $\left(\mathrm{kg} / \mathrm{m}^{2}\right)$, body mass index; $\mathrm{NC}(\mathrm{cm})$, neck circumference; AHI (/hr), apnea/hypopnea index; ODI (/hr), oxygen desaturation index; RDI (/hr), respiratory disturbance index; ESS, Epworth sleepiness score.

\section{Statistical Analysis}

The IBM SPSS software program version 20.0 was used to evaluate the data supplied to the computer (Armonk, NY, IBM Corp). Number and percent were used to describe qualitative data. The Kolmogorov-Smirnov test was employed to ensure that the distribution was normal. Mean, standard deviation SD, range (minimum and maximum), median, and interquartile range (IQR) were used to describe quantitative data. The significance of the acquired results was assessed at a 5\% level (statistically significant at $p \leq 0.05$ ). To compare different CPAP pressures, a $t$-test was used. The correlation was done by the Pearson correlation test. The Wilcoxon signed test of non-parametric data is abbreviated as $\mathrm{W}$, and used for assessment of continuous data differences. Scatter plot representation was used for the graphical analysis of the relationship between different pressures.

\section{Results}

This study included 48 adult patients with a mean \pm SD age of $49.98 \pm 10.36$ years with a range of $27.0-67.0$ years. The number of males was $23(47.9 \%)$ patients, and females were $25(52.1 \%)$ patients. Six patients $(12.5 \%)$ were diagnosed with mild OSA, 14 patients $(29.2 \%)$ had moderate OSA, and 28 patients (58.3\%) were diagnosed as severe as reported in Table 1, which shows different patient characteristics and anthropometrics.

All studied cases were included in the three different titration techniques. Data about the values of CPAP titration are introduced in Table 2, which shows that all patients were included in all titration techniques. The mean \pm SD values of measurable pressures were: $\mathrm{CPAP}_{\text {manual }}=10.44 \pm 2.49$ and $\mathrm{P} 95=10.16 \pm 2.64 \mathrm{cmH}_{2} \mathrm{O}$. The mean $\pm \mathrm{SD}$ values of calculated pressures were: Miljeteig and Hoffstein $=8.53 \pm 2.03$, Sériès $=11.40 \pm 1.81$, Stradling $=9.68 \pm 1.65$, Loredo $=9.90 \pm 1.79$, and Lee $=10.61$ $\pm 2.68 \mathrm{cmH}_{2} \mathrm{O}$.

The comparison between the standard pressure of manual titration and both P95 of APAP and calculated pressures by predictive formulas was assessed and and results are represented in Table 3. There was a statistically nonsignificant difference between $\mathrm{CPAP}_{\text {manual }}$ and $\mathrm{P} 95$

\begin{tabular}{|c|c|c|c|c|c|c|}
\hline Variables & \multicolumn{2}{|c|}{ Min. - Max. } & \multicolumn{2}{|c|}{ Mean \pm SD. } & \multicolumn{2}{|c|}{ Median (IQR) } \\
\hline Age (yrs) & \multicolumn{2}{|c|}{$27.0-67.0$} & \multicolumn{2}{|c|}{$49.98 \pm 10.36$} & \multicolumn{2}{|c|}{$51.50(42.50-57.0)$} \\
\hline BMI $\left(\mathrm{kg} / \mathrm{m}^{2}\right)$ & \multicolumn{2}{|c|}{$24.96-63.63$} & \multicolumn{2}{|c|}{$41.24 \pm 7.85$} & \multicolumn{2}{|c|}{$42.02(34.72-45.67)$} \\
\hline ESS $(>10)$ & \multicolumn{2}{|c|}{$0.0-23.0$} & \multicolumn{2}{|c|}{$10.75 \pm 5.35$} & \multicolumn{2}{|c|}{$11.0(7.0-15.0)$} \\
\hline STOP-BANG $\geq 3$ & \multicolumn{2}{|c|}{$1.0-7.0$} & \multicolumn{2}{|c|}{$4.77 \pm 1.36$} & \multicolumn{2}{|c|}{$5.0(4.0-6.0)$} \\
\hline AHI/hr & \multicolumn{2}{|c|}{$6.50-104.0$} & \multicolumn{2}{|c|}{$39.83 \pm 25.88$} & \multicolumn{2}{|c|}{$33.50(18.90-56.65)$} \\
\hline \multicolumn{7}{|l|}{ Sex } \\
\hline Male & \multicolumn{2}{|c|}{ NO } & 23 & \multicolumn{2}{|c|}{$\%$} & 47.9 \\
\hline Female & \multicolumn{2}{|c|}{ NO } & 25 & \multicolumn{2}{|c|}{$\%$} & 52.1 \\
\hline \multirow[t]{2}{*}{ Severity $(A H I / h r)$} & \multicolumn{2}{|c|}{ Mild (5-I5) } & \multicolumn{2}{|c|}{ Moderate (15-30) } & \multicolumn{2}{|c|}{ Severe $>\mathbf{3 0}$} \\
\hline & 6 & $12.5 \%$ & 14 & $29.2 \%$ & 28 & $58.3 \%$ \\
\hline
\end{tabular}
( $p=0.112$ ) with strong positive correlation as reported in Table 3 and Figure 1. Regarding $\mathrm{CPAP}_{\text {pred }}$, no significant differences were reported between manual pressure and

Table I Different Patient's Characteristics and Anthropometric Data 
Table 2 Descriptive Analysis of the Studied Cases $(n=48)$ According to CPAP Titration

\begin{tabular}{|l|l|c|c|c|}
\hline \multicolumn{2}{|l|}{ CPAP Titration } & Min. - Max. & Mean \pm SD. & Median (IQR) \\
\hline \multicolumn{2}{|l|}{ Manual $\left(\mathbf{c m H}_{\mathbf{2}} \mathbf{O}\right)$} & $5.0-15.0$ & $10.44 \pm 2.49$ & $11.0(9.25-12.0)$ \\
\hline P95 $\left(\mathbf{c m H}_{\mathbf{2}} \mathbf{O}\right)$ & $4.0-16.0$ & $10.16 \pm 2.64$ & $10.50(9.0-12.0)$ \\
\hline \multirow{2}{*}{ Equations $\left(\mathbf{c m H}_{\mathbf{2}} \mathbf{O}\right)$} & Miljeteig and Hoffstein & $4.60-12.60$ & $8.53 \pm 2.03$ & $8.70(6.80-9.95)$ \\
\cline { 2 - 6 } & Sériès & $7.60-16.00$ & $11.40 \pm 1.81$ & $11.4(9.85-12.91)$ \\
\cline { 2 - 6 } & Stradling & $7.0-13.20$ & $9.68 \pm 1.65$ & $9.55(8.25-11.0)$ \\
\cline { 2 - 5 } & Loredo & $7.50-14.07$ & $9.90 \pm 1.79$ & $9.20(8.56-10.80)$ \\
\cline { 2 - 5 } & Lee & $6.0-15.90$ & $10.61 \pm 2.68$ & $10.20(8.50-12.55)$ \\
\hline
\end{tabular}

Table 3 Comparison Between CPAP Manual Titration and Both Auto-Titrated P95 and Studied Predictive Formulas

\begin{tabular}{|l|c|c|c|c|c|c|}
\hline CPAP Titration & Mean & SD. & t-test & $\boldsymbol{P}$ & $\boldsymbol{P}$ & \\
\hline Manual titration & 10.44 & 2.49 & & & & \\
\hline Auto-titrated P95 & 10.16 & 2.64 & 0.653 & $0.112 \mathrm{NS}$ & 0.982 & $<0.00$ I $^{*}$ \\
\hline Miljeteig and Hoffstein equation & 8.53 & 2.03 & $5.366^{*}$ & $<0.00 I^{*} \mathrm{~S}$ & 0.421 & $0.003^{*}$ \\
\hline Sériès equation & 11.40 & $1.8 \mathrm{I}$ & 1.02 & $0.09 \mathrm{NS}$ & 0.345 & $0.016^{*}$ \\
\hline Stradling equation & 9.68 & 1.65 & 1.06 & $0.212 \mathrm{NS}$ & 0.594 & $<0.00 \mathrm{I}^{*}$ \\
\hline Loredo equation & 9.90 & 1.79 & 0.987 & $0.213 \mathrm{NS}$ & 0.433 & $0.002^{*}$ \\
\hline Lee equation & $10.6 \mathrm{I}$ & 2.68 & 0.447 & $0.657 \mathrm{NS}$ & 0.437 & $0.002^{*}$ \\
\hline
\end{tabular}

Note: *Statistically significant at $p \leq 0.05$.

Abbreviations: SD, standard deviation; $t, t$-test; $p, p$ value for comparing between manual pressure and other pressures (auto-titrated P95 and different equations); NS, non-significant; S, significant; $r$, Pearson coefficient.

calculated pressures by Sériès, Stradling, Loredo, and Lee equations ( $p=0.09,0.212,0.213$, and 0.657 , respectively) with positive correlations as shown in Table 3 and Figures 3-Figures 6, respectively. However, there was a highly significant difference with Miljeteig and Hoffstein equations $(p<0.001)$ as shown in Table 3 and Figure 2.

Table 4 presents the comparison between auto-titrated pressure and calculated pressure by other studies' predictive equations. It shows statistically non-significant differences with positive correlations with Sériès, Stradling, Loredo, and Lee equations $(0.101,0.142,0.502$, and 0.271 , respectively) for the comparison between the pressure of APAP and calculated pressures of predictive formulas; however, the difference was statistically significant with positive correlation with the Miljeteig and Hoffstein equation (0.04).
To assess the effectiveness of auto-titration, residual AHI after auto-titration was measured and compared with pretitration AHI that was measured by diagnostic polysomnography and reported a decrease of AHI with a high degree from 39.83 to residual $7.97 / \mathrm{hr}$ with a statistically highly significant change after auto-titration $(p<0.001)$ (Table 5).

\section{Discussion}

In our study, we compared manual titration as the standard method and between alternative titration methods (autotitration and predictive formulas) and also compared between auto-titration and predictive formulas.

Our results established that the CPAP level obtained by the standard method had no statistically significant difference with that acquired by the auto-titration and with 4 from 5 studied prediction formulas (Sériès, Stradling, Loredo, and Lee equations). 


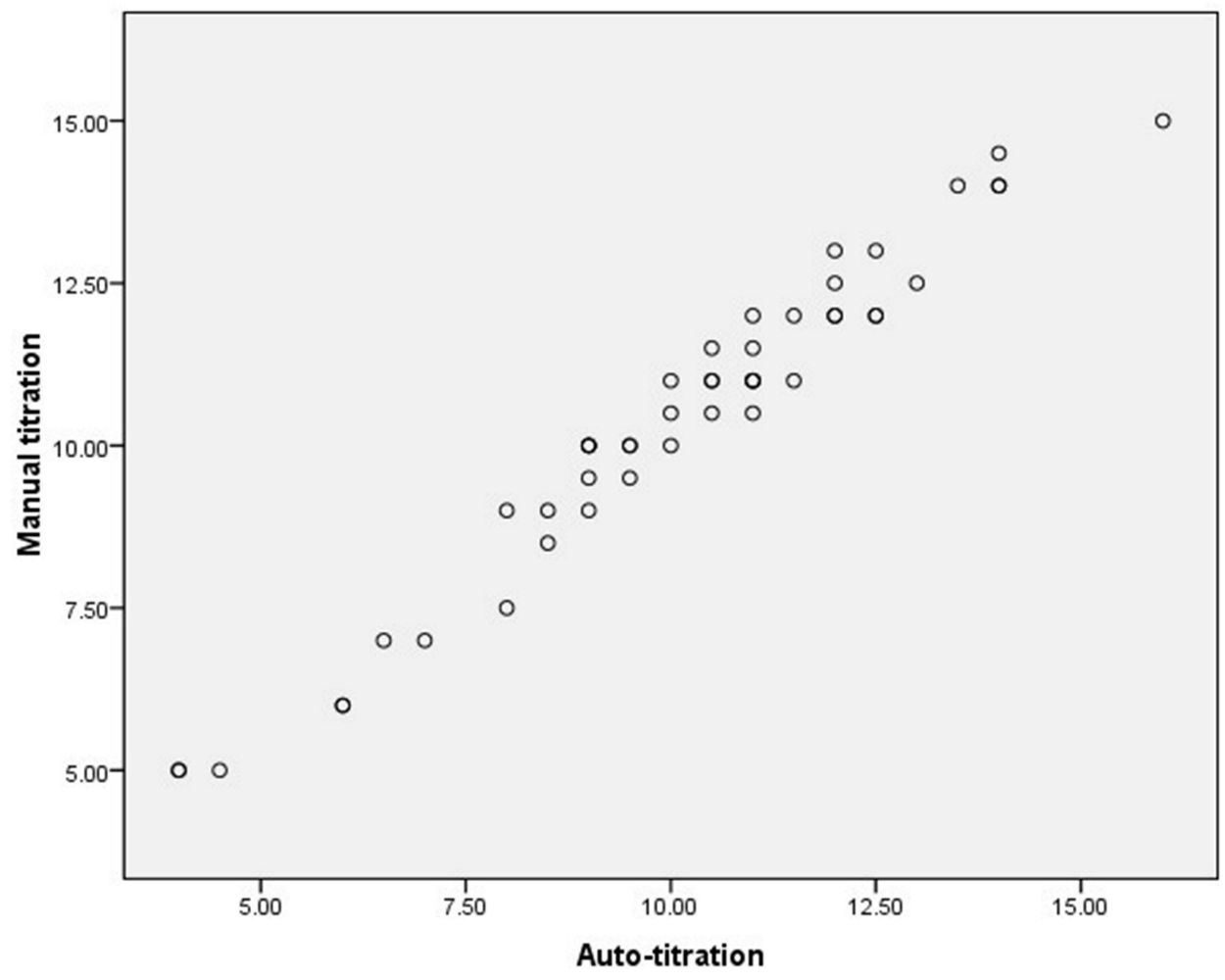

Figure I Scatter plot for manual titration and auto-titrated P95.

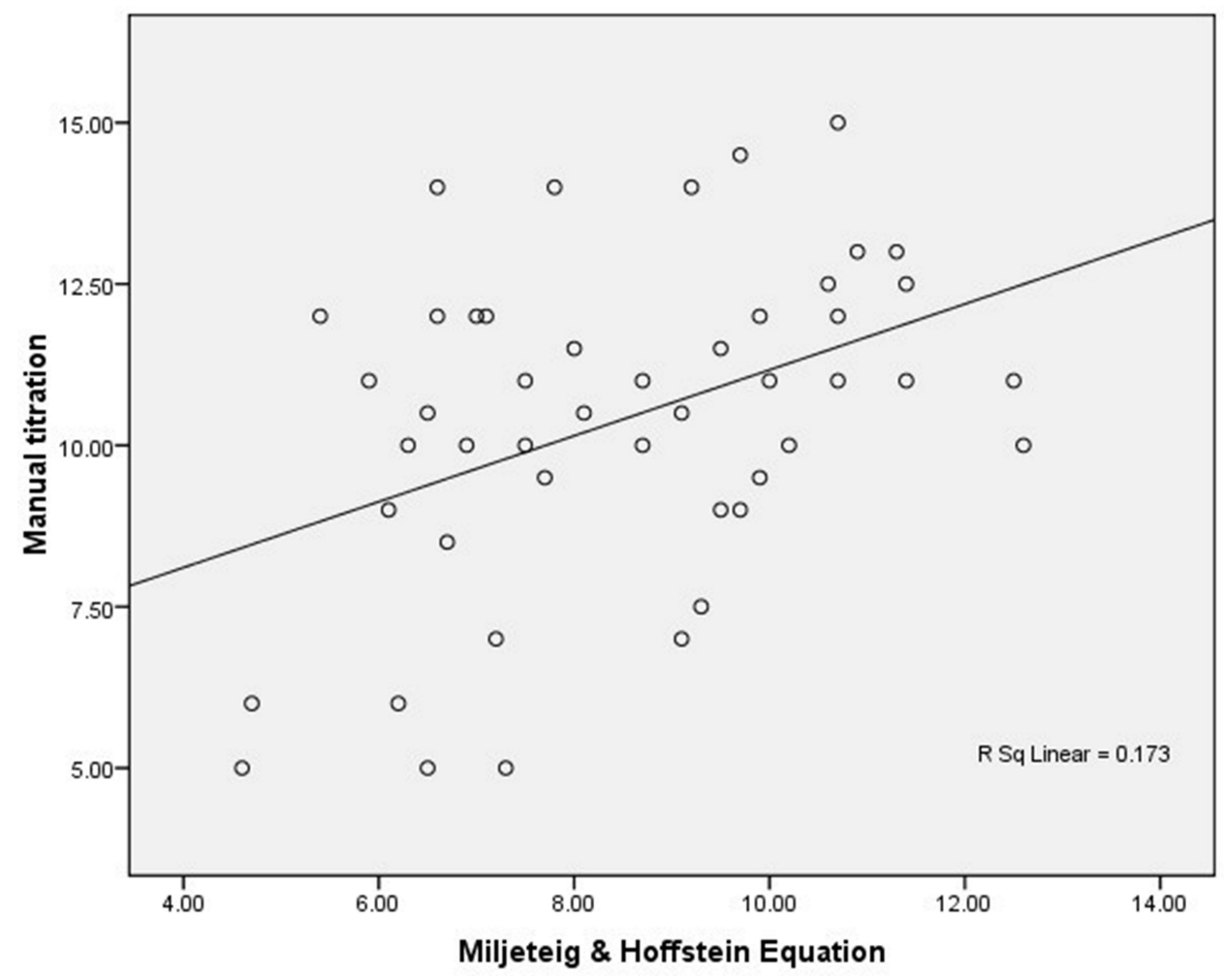

Figure 2 Scatter plot for manual titration and Miljeteig and Hoffstein equation. 


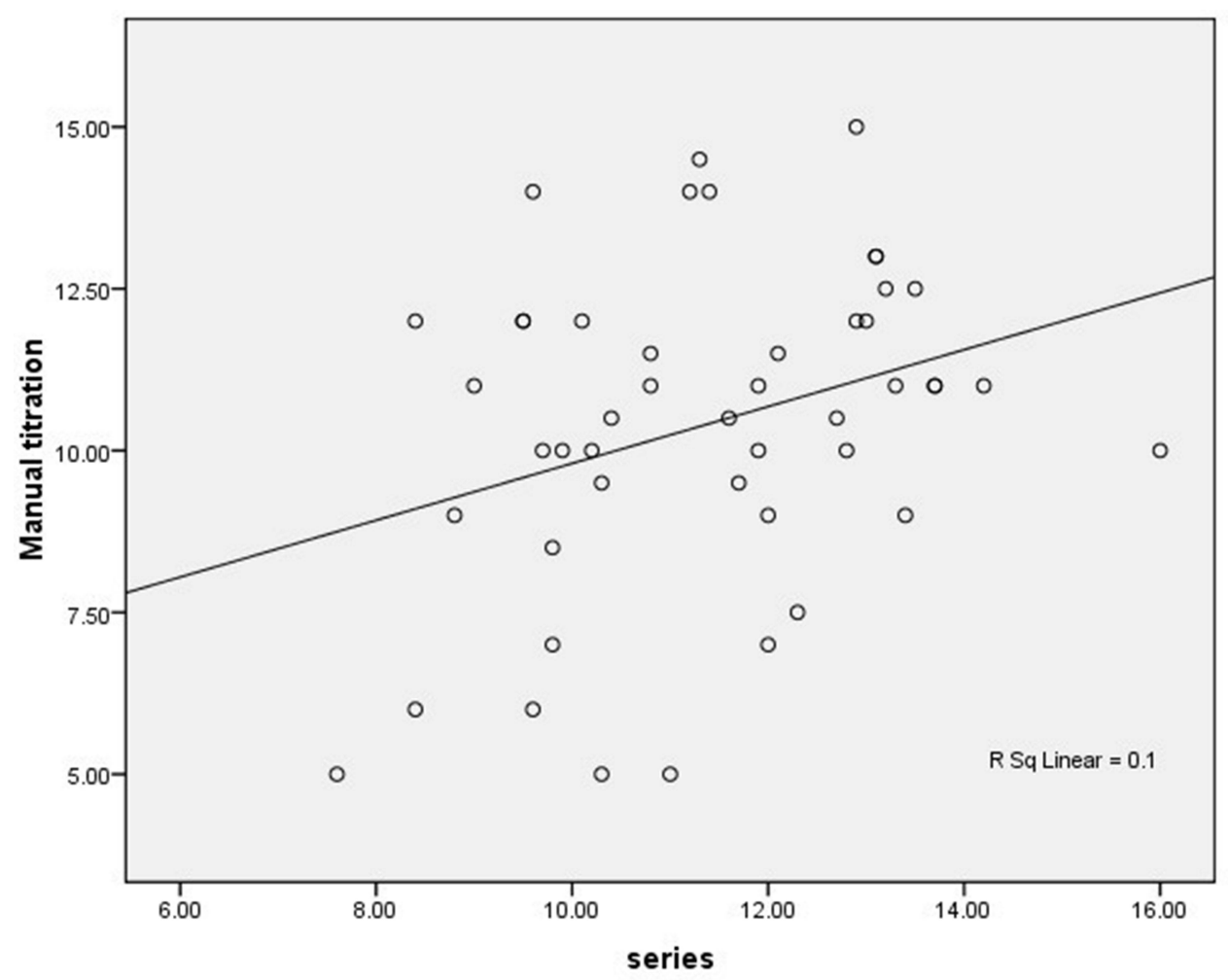

Figure 3 Scatter plot for manual titration and Sériès equation.

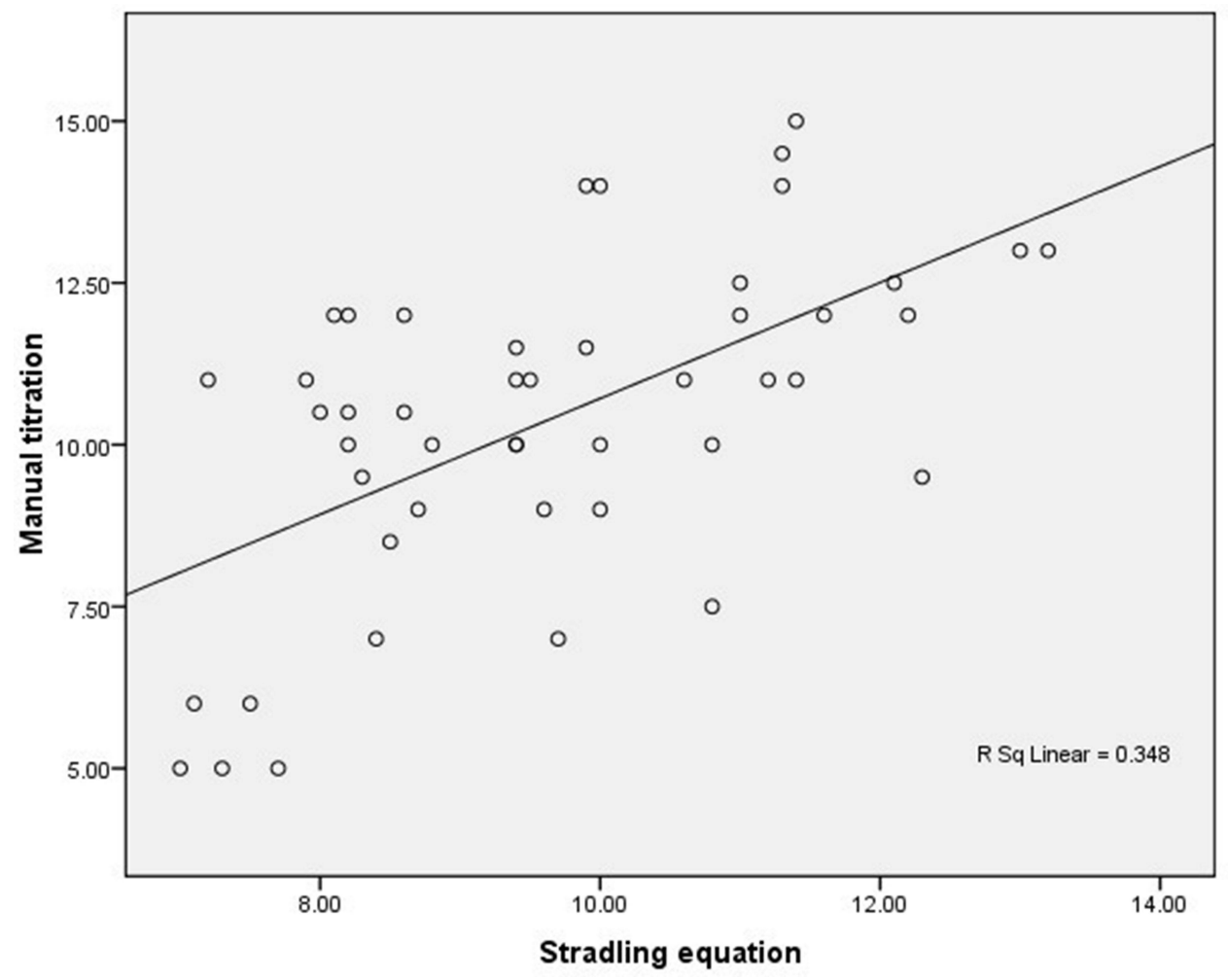

Figure 4 Scatter plot for manual titration and Stradling equation. 


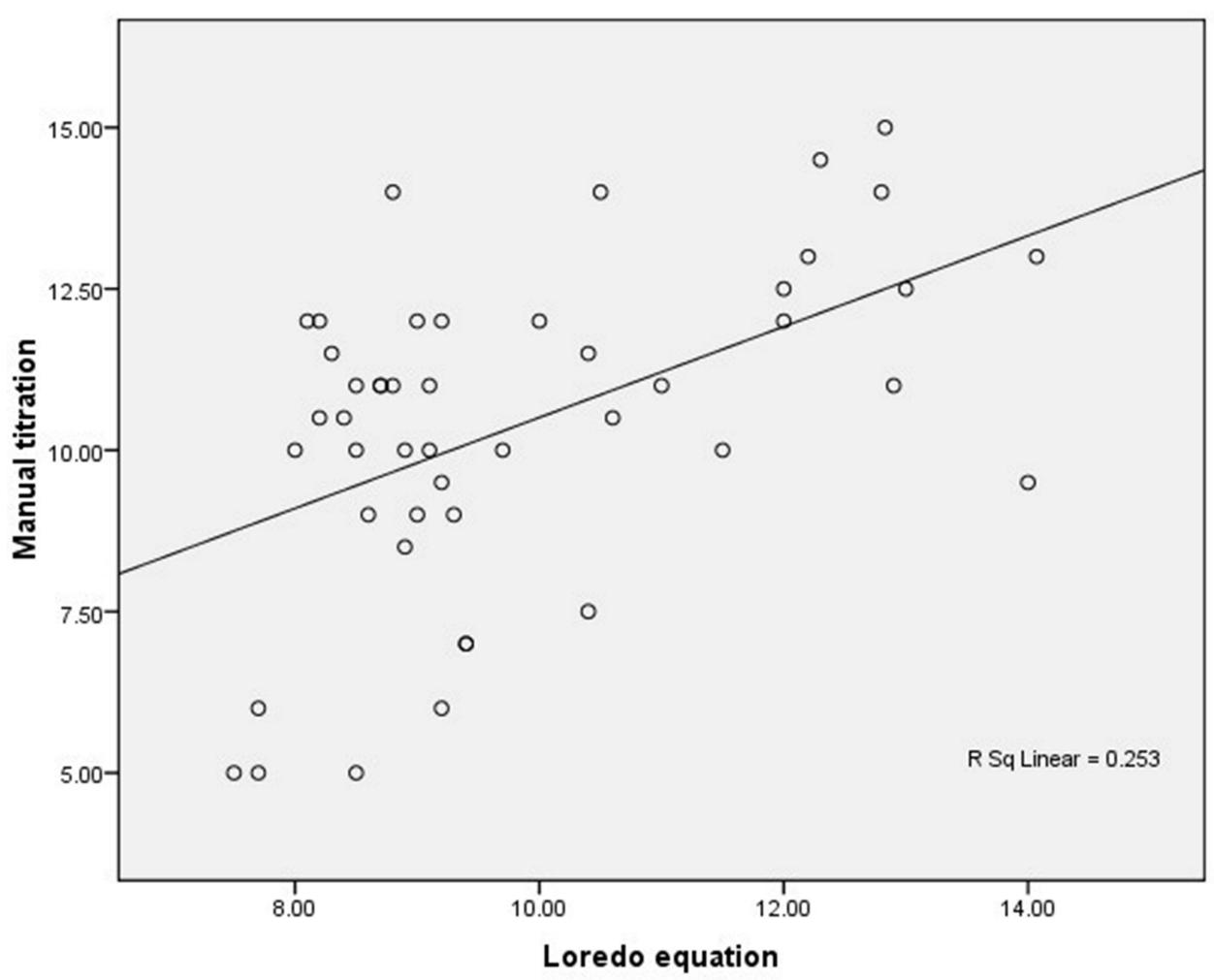

Figure 5 Scatter plot for manual titration and Loredo equation.

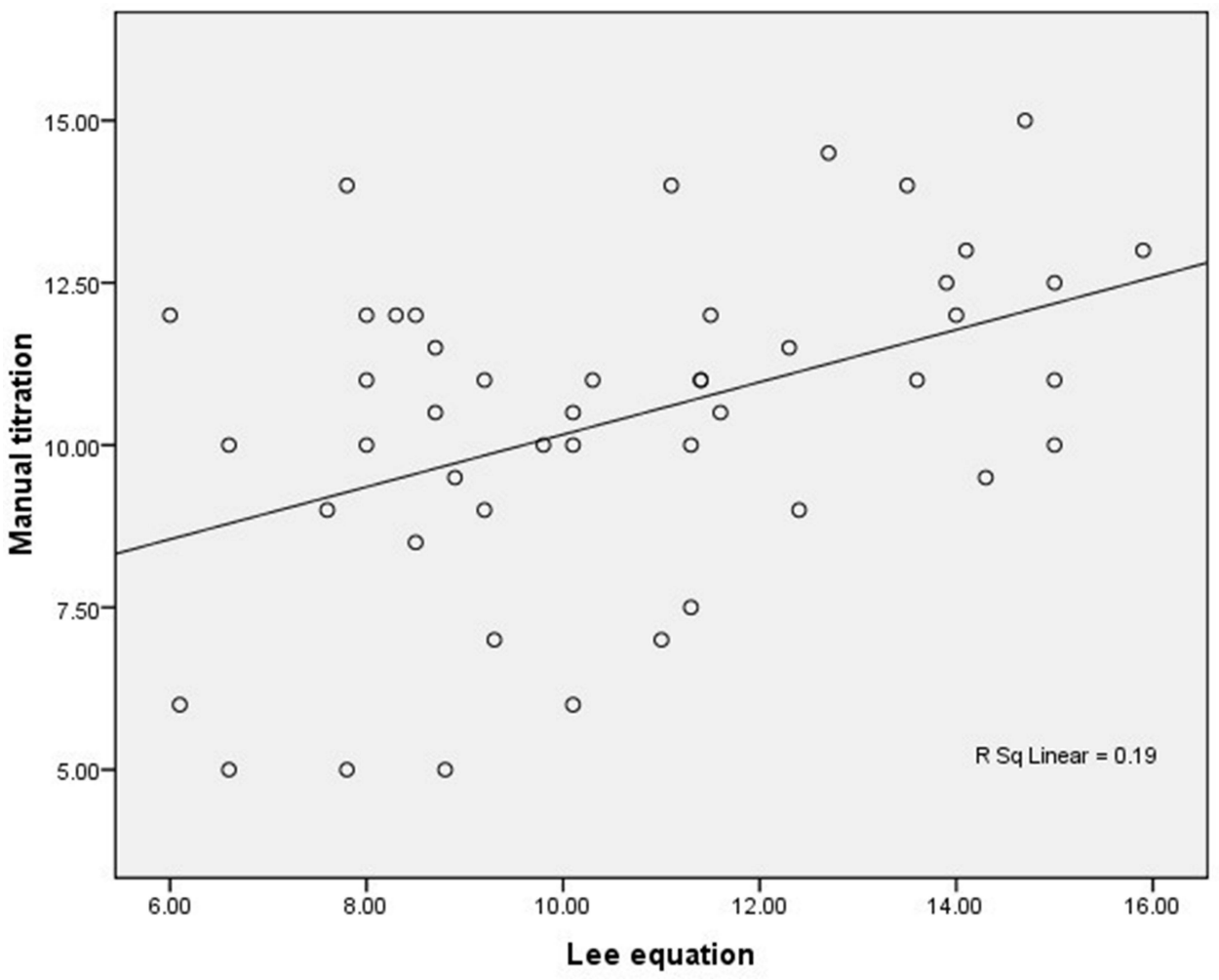

Figure 6 Scatter plot for manual titration and Lee equation. 
Table 4 Comparison Between Auto-Titrated P95 and Each Different Equation According to CPAP Titration

\begin{tabular}{|l|c|c|c|c|c|c|}
\hline CPAP Titration & Mean & SD. & t-test & $\boldsymbol{P}$ & $\boldsymbol{P}$ \\
\hline Auto-titrated P95 & 10.16 & 2.64 & & & & \\
\hline Equations & & & & & \\
\hline Miljeteig and Hoffstein equation & 8.53 & 2.03 & $2.34 I^{*}$ & $0.04^{*} \mathrm{~S}$ & 0.406 & $0.004^{*}$ \\
\hline Sériès equation & 11.40 & 1.81 & 0.691 & $0.101 \mathrm{NS}$ & 0.321 & $0.026^{*}$ \\
\hline Stradling equation & 9.68 & 1.65 & 1.495 & $0.142 \mathrm{NS}$ & 0.557 & $<0.00 \mathrm{I}^{*}$ \\
\hline Loredo equation & 9.90 & 1.79 & 0.779 & $0.502 \mathrm{NS}$ & 0.423 & $0.003^{*}$ \\
\hline Lee equation & $10.6 \mathrm{I}$ & 2.68 & 1.114 & $0.27 \mathrm{INS}$ & 0.427 & $0.003^{*}$ \\
\hline
\end{tabular}

Notes: *Statistically significant at $p \leq 0.05$.

Abbreviations: SD, standard deviation; $t, t$-test; $p$, $p$ value for comparing between auto-titrated P95 and different equations; NS, non-significant; $S$, significant; $r$, Pearson coefficient.

Table 5 Comparison Between Residual AHI After Auto-Titration and Baseline AHI/Hr

\begin{tabular}{|l|c|c|c|c|c|c|}
\hline AHI/hr & Mean & SD. & Median & Range & W & P \\
\cline { 1 - 5 } Auto-titration residual AHI/hr & 7.97 & 7.01 & 5.50 & $0-27$ & 6.58 & $<0.001 *$ \\
\cline { 1 - 5 } Baseline AHI/hr & 39.83 & 25.88 & 33.50 & $6.5-104$ & & \\
\hline
\end{tabular}

Notes: Mean, standard deviation (SD), range [minimum and maximum], median were used to describe quantitative data. W, Wilcoxon signed test of non-parametric data; $p$, $p$ value for comparing between baseline and residual AHI. * Statistically significant at $p \leq 0.05$.

Abbreviation: AHI, apnea hypopnea index/hr.

At the period of the discovery of CPAP, awareness of OSAS was still in its early stages, so the number of patients was relatively low. In recent years, individual CPAP titration has become a major logistic and financial burden owing to the large number of patients who suffer from OSAS. With the global obesity epidemic and the aging of the population, this challenge will continue to escalate in the coming years. ${ }^{18}$

Also, long waiting lists lead to delay in initiation of treatment, which is associated with increased morbidity and mortality risks, especially in severe OSAS patients. ${ }^{3}$

According to AASM guidelines, manual titration is the gold standard for measurement for appropriate CPAP treatment, and APAP devices should be used only for patients with uncomplicated moderate to severe OSAS, and in the presence of limited resources. ${ }^{19}$

In the era of the COVID-19 pandemic, positive airway pressure (PAP) devices are considered one of the routes of virus transmission. Due to aerosolization risk, the main World Associations of Sleep Medicine and the Center for Disease Control and Prevention (CDC) recommended postponing titration studies. ${ }^{20}$

It is reasonable to think about simplified alternative techniques leading to the same therapeutic efficacy.
Recently, several studies, especially after the COVID-19 pandemic, assessed the efficacy of alternative titration modalities by comparing the standard method with the same alternative methods used in our study and reported near-similar results or compared it with other methods. ${ }^{18,21-24}$

Demographic and resource features of our region make it very difficult to use self-adjusting home therapeutic strategies as a calibration or therapeutic option.

Our sleep lab was established at the end of 2015, and it was considered the first sleep lab in the Sharkia governorate. This research was the first in our governorate to evaluate the efficacy of auto-titration and different predictive formulas in order to investigate if any of them could replace the standard method in our Egyptian patients to reduce cost and effort, and in order to start treatment as early as possible.

In our study, the same device was used to compare attended auto-titration with the standard method, with no significant difference reported in our study between $\mathrm{CPAP}_{\text {manual }}$ and P95 of attended auto-titration, associated with a strong positive correlation. Also, several previous studies reported no significant difference regarding therapeutic pressure value between the two techniques. ${ }^{25-27}$ 
Other studies that depended on other titration techniques also reported near-similar results. Rosen et $\mathrm{al}^{28}$ and Kim et $\mathrm{al}^{21}$ carried out studies that compare PSG-guided laboratory titration and home auto-titration, and reported near-similar pressures with a statistically non-significant difference recorded for both methods. Also Shaarawy and Gharraf reported no significant difference between manual and auto-titration during split-night study $(p=0.06) .{ }^{29}$

On the other hand, this contradicts Ficker et al, who only compared a single night therapy with REM+auto device with constant pressure CPAP. During auto-CPAP, the mean pressure was significantly higher than during standard CPAP $(p<0.05) .{ }^{30}$ Considering the spontaneous variability from night to night in the architecture of sleep and OSAS severity, this study design was not adequate for detecting small differences between the two strategies of treatment. Luo et al reported a highly significant difference between manual titration pressure by virtuoso, Respironics, and automatic titration (P90) by REMstar Auto $(p<0.001) .^{31}$

The differences in results were because the included studies used different auto-titration protocols. The testing devices are not identical due to the differences in manufacturer's and sleep technicians' experience, which is the source of the heterogeneity. Differences in baseline characteristics of subjects may also be another cause for variability. ${ }^{5}$

The disparities between manual titration and autotitration could be attributable to variances in how parameters like snoring, apnea, and hypopnea are evaluated; also, different recording methods were used. During manual titration with PSG guidance, the respiratory effort was measured using an elastic band across the thoracic/abdominal region, as well as oxygen saturation and electroencephalography (EEG). Auto-titration pressures, on the other hand, were automatically determined by the machine's algorithm without respiratory effort, body position, EEG, or oxygen saturation recordings. ${ }^{26}$

To ensure the effectiveness of auto-titration, residual $\mathrm{AHI} / \mathrm{hr}$ after auto-titration was recorded and showed a significant decrease compared with baseline, with a statistically highly significant change.

This result was in accordance with several studies such as Hussain et al, ${ }^{32}$ Masa et al, ${ }^{33}$ Fietze et al, ${ }^{34}$ Galetke et al, ${ }^{35}$ Galetke et al, ${ }^{36}$ and Shaarawy and Gharraf ${ }^{29}$ who reported a significant difference between baseline $\mathrm{AHI} / \mathrm{hr}$ and after APAP, one with marked improvement.
Regarding the comparison between standard manual titration and mathematical algorithms in this study, manual titration has positive correlations with statistically nonsignificant differences with the Sériès, Stradling, Loredo, and Lee equations. However, there is a statistically significant difference between CPAP titration pressures by manual titration and the Miljeteig and Hoffstein equation, which is lower than the standard.

Near-similar results were reported by Lacedonia et al who compared 3 predictive formulas (Stradling, Sériès, and Hoffstein), which were also used in our study, with both manual and auto-titration, and found that there were no differences in the determined pressures by Stradling and Sériès equations, and the titrated pressure, but significant difference in the pressure determined by the Miljeteig and Hoffstein equation. ${ }^{25}$

According to Sadeghniiat-Haghighi et al, there was a statistically non-significant difference between mean pressure measured by manual method and the Loredo et $\mathrm{al}^{16}$ formula, similar to our results; however, the differences were statistically significant when compared with calculated pressures, measured by Miljeteig and Hoffstein, ${ }^{13}$ Lin et al, ${ }^{38}$ and Hukins ${ }^{39}$ equations. ${ }^{37}$

Lee et al reported, in a study on Asians, that there was a positive correlation with no significant difference between the mean of manual titration pressure and of developed formula. Because Asian study subjects are less obese than Western subjects, the Hoffstein equation tended to underestimate the appropriate CPAP level in this study when compared to the created equation. Also, Asian subjects exhibited more craniofacial bony restriction. ${ }^{17}$

In 2021, the same result was reported by Matias et al who reported a highly significant difference between manual titration and the Miljeteig and Hoffstein equation. ${ }^{3}$

Different results were reported by Oliver and Hoffstein $^{40}$ and Masa et al, ${ }^{33}$ who reported that there was no significant difference between CPAP titration pressure and Miljeteig and Hoffstein equation predicted pressure. The first study used a manual titration approach that was relatively unique and personalized, and they did not compare it to any other approaches. In the other study, predicted formula pressures were used after domiciliary adjustment.

In a comparison between P95 by auto-titration and other pressures that were calculated by predictive formulas, we reported statistically non-significant differences between P95 and Sériès, Stradling, Loredo, and Lee equations $(0.101,0.142,0.502$, and 0.271 , respectively), but 
there was a statistically significant difference with the Miljeteig and Hoffstein equation.

This is in accordance with the findings of Wahab and Ahmed, who found that the measured pressure using the Hoffstein equation was significantly much lower than P90 of auto-CPAP. The calculated pressures using the other four algorithms (Sériès, Stradling, Loredo, and Lee equations) and P90\% were not significantly different. ${ }^{41}$

The significant difference between the Hoffstein formula and other studied methods makes this equation usually not suitable for determining ideal pressure. This can be explained by the absence of variables that influence the severity of OSAS as this equation takes into account AHI, NC, and BMI, but not race or lifestyle. ${ }^{3,42}$

Although the variables in the Sériès equation were the same as in the Miljeteig and Hoffstein equation, the calculated pressure using their algorithm was statistically not different from P95\%. The distinction is that in the Sériès equation a small constant was subtracted from the algorithm, whereas in the Hoffstein equation a large constant was subtracted ( 0.611 vs 5.12 , respectively). ${ }^{41}$

According to Lacedonia et al, manual or auto-titration is still the best approach to determine the therapeutic pressure. Predictive formulas, on the other hand, can be valuable if applied with prudence and after establishing the true efficacy. ${ }^{25}$

Construction of own predictive formula for determining the effective pressure is not necessary; the formula that was derived from the same ethnicity can be adopted and used for the reference formula. ${ }^{43}$

The limitations of our study include the fact that the studied patients were derived from only one sleep unit, which could lead to sampling bias. To investigate OSAS risk factors in our country, multicenter research is required. In addition, only adult patients were involved in this study, so our results cannot be applied to children who have OSAS. Lastly, our study lacks follow-up of patients for long periods to evaluate the effectiveness of CPAP treatment after different titration modalities.

Further studies should evaluate the degree of improvement according to clinical and polysomnographic data, compliance, and adherence to treatment after each titration modality, especially of different predictive formulas.

Also, future studies are suggested to assess the efficacy of easier, more accurate, and simple titration techniques such as home auto-titration and split-night studies.

\section{Conclusion}

According to the guidelines, manual titration is recommended as the gold standard for CPAP titration, and APAP devices should be used only for patients with uncomplicated moderate to severe OSAS, and in the presence of limited resources, but there are some limitations for manual titration including increased cost, effort, and time. Alternative titration modalities (auto-titration and predictive formulas) can be used with similar efficiency as the standard method with less cost, effort, and time.

After the COVID-19 pandemic, predictive formulas are considered the safest titration method that can be used to start treatment without delay in patients with OSAS, especially those who had serious symptoms and or uncontrolled comorbidities.

\section{Abbreviations}

AASM, American Academy of Sleep Medicine; AHI, apnea/hypopnea index; APAP, auto-titration positive airway pressure; BMI, body mass index; CDC, Center for Disease Control and Prevention; CPAP, continuous positive airway pressure; EEG, electroencephalography; ESS, Epworth sleepiness scale; NC, neck circumference; ODI, oxygen desaturation index; OSAS, obstructive sleep apnea syndrome; PAP, positive airway pressure; PSG, polysomnography; RDI, respiratory disturbance index; SPL, split night; UHPSM, unattended home partial sleep monitoring.

\section{Ethics Approval and Consent to Participate}

This study was approved by the administrative council of the chest department and institutional board review of Zagazig University (ZU-IRB \#4745/30-7-2018). Patients included in this study gave their informed and signed consent.

\section{Acknowledgments}

The authors express their gratitude to all of the study participants and investigators.

\section{Funding}

This study did not obtain any specific support from public, commercial, or nonprofit funding agencies.

\section{Disclosure}

The authors reported no conflicts of interest in this work. 


\section{References}

1. Knauert M, Naik S, Gillespie MB, Kryger M. Clinical consequences and economic costs of untreated obstructive sleep apnea syndrome. World J Otorhinolaryngol. 2015;1(1):17-27. doi:10.1016/j. wjorl.2015.08.001

2. Ip S, D'Ambrosio C, Pate K, et al. Auto-titrating versus fixed continuous positive airway pressure for the treatment of obstructive sleep apnea. A systematic review with meta-analyses. Syst Rev. 2012;1 (1):1-24. doi:10.1186/2046-4053-1-20

3. Matias B, Chiapella MN, Fernandez A, Guardia S. CPAP pressure prediction calculation. An Alternative to the difficulty of performing a titration within the context of the COVID19 pandemic. RAMR. 2021;2:144-150.

4. Ebben MR, Narizhnaya M, Krieger AC. A new predictive model for continuous positive airway pressure in the treatment of obstructive sleep apnea. Sleep Breath. 2017;21:435-442. doi:10.1007/s11325016-1436-7

5. Gao W, Jin Y, Wang Y, et al. Is automatic CPAP titration as effective as manual CPAP titration in OSAHS patients? A meta-analysis. Sleep Breath. 2012;16(2):329-340. doi:10.1007/s11325-011-0495-z

6. Marrone O, Salvaggio A, Romano S, Insalaco G. Automatic titration and calculation by predictive equations for the determination of therapeutic continuous positive airway pressure for obstructive sleep apnea. Chest. 2008;133(3):670-676. doi:10.1378/chest.07-1372

7. Planes C, d'Ortho MP, Foucher A, et al. Efficacy and cost of home-initiated autonCPAP versus conventional nCPAP. Sleep. 2003;26:156-160. doi:10.1093/sleep/26.2.156

8. Deutsch PA, Simmons MS, Wallace JM. Cost-effectiveness of split-night polysomnography and home studies in the evaluation of obstructive sleep apnea syndrome. J Clin Sleep Med. 2006;2 (2):145-153. doi:10.5664/jcsm.26508

9. Epstein LJ, Kristo D, Strollo PJ, et al. Clinical guideline for the evaluation, management and long-term care of obstructive sleep apnea in adults. J Clin Sleep Med. 2009;5(3):263-276.

10. American Academy of Sleep Medicine. International Classification of Sleep Disorders. 3rd ed. Darein, IL: American Academy of Sleep Medicine. CHEST; 2014.

11. Nava S, Hill N. Non-invasive ventilation in acute respiratory failure. Lancet. 2009;374(9685):250-259. doi:10.1016/S0140-6736(09) 60496-7

12. McArdle N, Singh B, Murphy M, et al. Continuous positive airway pressure titration for obstructive sleep apnoea: automatic versus manual titration. Thorax. 2010;65(7):606-611. doi:10.1136/thx.2009.116756

13. Miljeteig H, Hoffstein V. Determinants of continuous positive airway pressure level for treatment of obstructive sleep apnea. Am Rev Respir Dis. 1993;147(6 pt 1):1526-1530. doi:10.1164/ajrccm/ 147.6_Pt_1.1526

14. Sériès F. Accuracy of an unattended home CPAP titration in the treatment of obstructive sleep apnea. Am J Respir Critical Care Med. 2000;162(1):94-97. doi:10.1164/ajrccm.162.1.9908023

15. Stradling JR, Hardinge M, Paxton J, Smith DM. Relative accuracy of algorithm-based prescription of nasal CPAP in OSA. Respir Med. 1994;98(2):152-154. doi:10.1016/j.rmed.2003.09.009

16. Loredo JS, Berry C, Nelesen RA, Dimsdale JE. Prediction of continuous positive airway pressure in obstructive sleep apnea. Sleep Breath. 2007;11(1):45-51. doi:10.1007/s11325-006-0082-x

17. Lee GH, Kim MJ, Lee EM, Kim CS, Lee SA. Prediction of optimal CPAP pressure and validation of an equation for Asian patients with Obstructive Sleep Apnea. Respir Care. 2013;58(5):810-815. doi: $10.4187 /$ respcare. 01860

18. Farré R, Gozal D, Montserrat JM. Alternative Procedure to Individual Nasal Pressure Titration for Sleep Apnea. J Clin Med. 2021;10:1-7. doi: $10.3390 /$ jcm 10071453
19. Littner M, Hirshkowitz M, Davila D, et al. Practice parameters for the use of auto-titrating continuous positive airway pressure devices for titrating pressures and treating adult patients with obstructive sleep apnea syndrome. An American Academy of Sleep Medicine report. Sleep. 2002;25:143-147. doi:10.1093/ sleep/25.2.143

20. Rodríguez CY, Valiensi S. Recomendaciones para laboratorios de sueño durante la pandemia por Coronavirus. Rev Am MedResp. 2020;1:14-24.

21. Kim JS, Kang YJ, ChS P, Hwang JH, Kim YJ. Clinical Parameters Related to the Duration of Automatic Positive Airway Pressure Titration. Sleep Med Res. 2020;11(1):31-37. doi:10.17241/ smr.2020.00521

22. Unnithan AS, Krishna GG, Lakshmanan PH. Efficacy of auto-PAP titration in obstructive sleep apnea: single-center experience. Indian J Respir Care. 2020;9:68-70. doi:10.4103/ijrc.ijrc_35_19

23. Kido K, Tachibana N. The new procedure for manual CPAP titration: theafternoon CPAP titration (aPT). J Med Invest. 2021;68:170-174. doi:10.2152/jmi.68.170

24. Rezk NA, Algamal M, Mohy S, Morsy NE, Abo Shehata MA. Druginduced sleep endoscopy as a new modality for continuous positive airway pressure titration. Egypt $J$ Chest Dis Tuberculosis. 2021;70:403-411. doi:10.4103/ejcdt.ejcdt_148_20

25. Lacedonia D, Sabato R, Carpagnano GE, et al. Predictive equations for CPAP titration in OSAS patients. Sleep Breath. 2012;16 (1):95-100. doi:10.1007/s11325-010-0461-1

26. Berry RB, Sriram P. Auto-adjusting positive airway pressure treatment for sleep apnea diagnosed by home sleep testing. J Clin Sleep Med. 2014;10(12):1269-1275. doi:10.5664/jcsm.4272

27. Vennelle M, White S, Riha RL, Mackay T, Engleman HM, Douglas NJ. Randomized controlled trial of variable-pressure versus fixed pressure continuous positive airway pressure (CPAP) treatment for patients with obstructive sleep apnea/hypopnea syndrome (OSAHS). SLEEP. 2010;33(2):267-271. doi:10.1093/sleep/ 33.2.267

28. Rosen CL, Auckley D, Benca R, et al. A multisite randomized trial of portable sleep studies and positive airway pressure autotitration versus laboratory-based polysomnography for the diagnosis and treatment of obstructive sleep apnea: the HomePAP study. Sleep. 2012;35 (6):757-767. doi:10.5665/sleep. 1870

29. Shaarawy H, Gharraf HS. Comparison between the use of APAP and manual titration during split night polysomnography for diagnosis and treatment of OSA. Egypt. J Chest Dis Tuberc. 2018;67 (2):175-181. doi:10.4103/ejcdt.ejcdt_20_18

30. Ficker JH, Wiest GH, Lehnert G, Wiest B, Hahn EG. Evaluation of an autoCPAP device for treatment of obstructive sleep apnoea. Thorax. 1998;53(8):643-648. doi:10.1136/thx.53.8.643

31. Luo J, Xiao S, Qiu Z, Song N, Luo Y. Comparison of manual versus automatic continuous positive airway pressure titration and the development of a predictive equation for therapeutic continuous positive airway pressure in Chinese patients with obstructive sleep apnoea. Respirology. 2013;18(3):528-533. doi:10.1111/resp.12014

32. Hussain SF, Love L, Burt H, Fleetham JA. A randomized trial of auto-titrating CPAP and fixed CPAP in the treatment of obstructive sleep apnea-hypopnea. Respir Med. 2004;98(4):330-333. doi:10.1016/j.rmed.2003.11.002

33. Masa JF, Jimenez A, Duran J, et al. Alternative methods of titrating continuous positive airway pressure: a large multicenter study. Am J Respir Crit Care Med. 2004;170(11):1218-1224. doi:10.1164/ rccm.200312-1787OC

34. Fietze I, Glos M, Moebus I, Witt C, Penzel T, Baumann G. Automatic pressure titration with APAP is as effective as manual titration with CPAP in patients with obstructive sleep apnea. Respiration. 2007;74 (3):279-286. doi:10.1159/000100364 
35. Galetke W, Anduleit N, Richter K, Stieqlitz S, Randerath WJ. Comparison of automatic and continuous positive airway pressure in a night-by-night analysis: a randomized, crossover study. Respiration. 2008;75(2):163-169. doi:10.1159/000097767

36. Galetke W, Randerath WJ, Stieglitz S, et al. Comparison of manual titration and automatic titration based on forced oscillation technique, flow and snoring in obstructive sleep apnea. Sleep Med. 2009;10 (3):337-343. doi:10.1016/j.sleep.2008.03.007

37. Sadeghniiat-Haghighi K, Rahimi-Golkhandan A, Najafi A, Arshi S, Jamshidi S. Using prediction formulas for continuous positive airway pressure in obstructive sleep apnea syndrome. J Sleep Sci. 2018;3(34):75-79. doi:10.1016/j.sleep.2019.11.763

38. Lin IF, Chuang ML, Liao YF, et al. Predicting effective continuous positive airway pressure in Taiwanese patients with obstructive sleep apnea syndrome. JFormos Med Assoc. 2003;102(4):215-221.
39. Hukins CA. Arbitrary-pressure continuous positive airway pressure for obstructive sleep apnea syndrome. Am J Respir Crit Care Med. 2005;171(5):500-505. doi:10.1164/rccm.200401-0190C

40. Oliver Z, Hoffstein V. Predicting effective continuous positive pressure. Chest. 2000;117(4):1061-1064. doi:10.1378/chest.117.4.1061

41. Wahab NA, Ahmed YN. Optimal level of continuous positive airway pressure: auto-CPAP titration versus predictive formulas. Egypt J Chest Dis Tuberc. 2016;66:353-361. doi:10.1016/j.ejcdt.2016.11.004

42. Villaneuva AT, Buchanan PR, Yee BJ, Grunstein RR. Ethnicity and obstructive sleep apnoea. Sleep Med Rev. 2005;9(6):419-436. doi:10.1016/j.smrv.2005.04.005

43. Wu MF, Hsu JY, Huang WC, et al. Should sleep laboratories have their own predictive formulas for continuous positive airway pressure for patients with obstructive sleep apnea syndrome? J Chin Med Assoc. 2014;77(6):283-289. doi:10.1016/j.jcma.2014.02.015

\section{Publish your work in this journal}

The International Journal of General Medicine is an international, peer-reviewed open-access journal that focuses on general and internal medicine, pathogenesis, epidemiology, diagnosis, monitoring and treatment protocols. The journal is characterized by the rapid reporting of reviews, original research and clinical studies across all disease areas. The manuscript management system is completely online and includes a very quick and fair peer-review system, which is all easy to use. Visit http://www.dovepress.com/ testimonials.php to read real quotes from published authors. 